\title{
African Traditional Vegetables as Agents of Integrated Soil Fertility Manangement-Crotalaria and Amaranth
} Farming

\author{
Maina Mwenya Muniafu, Abdalla Muniafu Malala and Moses Oloo Kwena \\ School of Pharmacy and Health Sciences, United States International University (USIU), P.O. Box 14634, Nairobi 00800, Kenya
}

\begin{abstract}
The knowledge and understanding of African leafy vegetables has diminished over time, but in the recent past year there is more interest in their research for their nutritive and medicinal values. Of value are those that have the potential to ameliorate soil nutrient levels. This is with the background that despite inorganic fertilizers (IF) have a dramatic impact on agriculture in the world, the economic situation in Sub-Saharan African calls for alternative methods to reduce soil fertility degradation. The use of leguminous vegetables may be a solution. The study looks at the potential contribution of a leguminous traditional vegetableCrotalaria brevidens to soil nitrogen under various treatments. During the study which was conducted over two seasons, $C$. brevidens was grown under two treatments of IF and organic fertilizer (OF) with a control in which there was no fertilizer (NF) applied. A non-leguminous vegetable-Amaranthus dubious (Amaranth) was grown under the same treatments for comparison purposes. Soil analysis was done before and after planting in the treatment subplots. Growth parameters were measured every fortnight and these included leaf number, shoot length, dry weight and nodule number for Crotalaria. Results indicated that the leguminous vegetable was not affected by external inputs and there were no significant differences between treatments and control. The non-leguminous vegetables responded well to both IF and OF treatments in all the measured parameters. This underlines the potential for improving soil nitrogen levels using leguminous vegetables, especially as intercrops with the non-leguminous types.
\end{abstract}

Key words: Leafy vegetables, soil nitrogen, root nodules, soil fertility.

\section{Introduction}

Appropriate human nutrition as well as food security in Africa has both been key issue that countries on the continent face. Attaining suitable levels for both has been made more challenging by various factors which are complicated by the ever rising population numbers. Thus, as an end result, cases of malnutrition have been on the rise in recent times. It is a fact that commendable drives have been made to improve food security in some regions through concerted efforts of boosting agricultural productivity and enhancing the availability of inorganic nutrients, water and other resources. However, more often than not, the very same efforts

Corresponding author: Maina Mwenya Muniafu, associate professor, research field: natural sciences. E-mail: mmuniafu@usiu.ac.ke. lead to land degradation, further compromising the efforts to increase food production, which means that many countries then struggle to feed their citizens. Urbanization has also contributed to malnutrition mainly through lifestyle changes. People tend to embrace foods that are easy to cook and are considered modern in nature. This trend has led to neglect of the traditional foods and vegetable which have high nutritional values.

Like many other plants on the continent of Africa, the role and understanding of African leafy vegetables is diminishing, as people became more and more urbanized in their livelihoods. Such vegetables were then associated with poverty or a lack of sophistication. In the past, they were collected from the wild, and in addition to being dietary items, they also had a useful medicinal role. In recent years, however, there has been a realization of their potential 
to contribute to better health, and this has invariably led to more studies of various aspects of these plants, such as agronomy for cultivation purposes. Indigenous vegetables tend to have short production cycles, require intensive labour (but few purchased inputs) and produce high yields with strong nutritional value. They can therefore support rural, peri-urban and urban populations both in terms of subsistence cultivation and as market products, without requiring large capital investments. For this reason, they are also becoming popular among commercial growers in some areas [1].

This study went a stage further and aimed at assessing the contribution of a leguminous vegetable-Crotalaria brevidens to soil nitrogen levels. A non-leguminous vegetable-Amaranthus cruentus was selected for comparison purposes.

Soil fertility degradation is widely acknowledged as a major factor of limiting productivity of the Sub-Saharan Africa smallholder farming systems. The use of inorganic fertilizers (IF) has technically been considered as a solution for restoring this soil fertility. However, IF have been linked to numerous environmental hazards, including marine eutrophication, global warming, groundwater contamination and stratospheric ozone destruction [2]. This has meant that in many industrialized countries, research interests in low-external-input agriculture are largely driven by overproduction and concerns of the environmental effects of intensive agrochemical use. In the less industrialized countries, interest in low-external-input agriculture is often a necessity, which is fuelled by the lack of access to high input approaches due to either local or national economics [3]. These include unreliable returns from limited access to capital by smallholders and unreliable markets for agricultural produce. The use of manure is limited because the quantities available on-farm are often insufficient to maintain soil fertility.

Nitrogen input, through growing of legumes, is a feasible option. The legumes are important as a component of an integrated soil fertility management
(ISFM) strategy, since nutrients such as phosphorus (P) have to be acquired from elsewhere [4]. Eventually, the growing of these vegetables shall help improve the current status of human nutrition.

\section{Materials and Methods}

The experimental design was a randomized block design, consisting of three treatments and one replicate for each of the two vegetables selected. A plot of land about $10 \mathrm{~m} \times 6 \mathrm{~m}$ was subdivided into 15 subplots of about $2 \mathrm{~m} \times 2 \mathrm{~m}$ each. The three treatments were IF, organic fertilizer (OF) and no fertilizer (NF) application. Each treatment was replicated three times in a random manner within the experiment site. Sowing for season one was done on May 15, 2012 and followed by season two following recommendations for such vegetables by the Ministry of Agriculture Handbook (2001); and all the subplots received water to saturation point on every fourth days of the week. Prior to this, three soil samples were collected from each subplot to a depth of $20 \mathrm{~cm}$, mixed in a composite sample and taken for analysis to the soil testing labs of the Kenya Agricultural Research Institute, Westlands. The OF used was made earlier using alternate layers of cow manure, plant leaves, flowers and grass waste collected from the surrounding areas, while the IF was commonly used as commercial fertilizer diammonium phosphate (DAP). All the treatments were subjected to common conditions and closely monitored for any changes that could arise. Plant growth was monitored through harvesting of three plants from every replicate plot once every two weeks. Parameters measured included stem length, leaf numbers and numbers of nodules for the leguminous varieties. Final harvest was done 60 days after sowing (DAS) and soil samples were again collected for soil analysis at the end of each growing season.

\section{Results}

\subsection{Analysis of Soil and Organic Manure}

Nutrient levels in the soil collected from the experiment plot before treatment application showed 
adequate levels of macro and micro nutrients as indicated in Table 1, while soil nitrogen levels after the growing season are shown in Table 2 .

\subsection{Amaranthus dubius}

\subsubsection{Number of Leaves}

The IF treatment recorded the highest mean leaf number in both seasons (Figs. 1 and 2, Tables 3 and 4). Leaf number in OF treatment showed marked increases from 10th week in both seasons, while that of the control was the lowest (up to 50\%) in all weeks in both seasons. The differences between the treatments and the control were highly significant $(P<$ 0.001 ), while that between the two treatments was not significant in both seasons.

\subsubsection{Shoot Length}

The IF treatment recorded the highest mean shoot length in both seasons (Figs. 3 and 4, Tables 5 and $6)$. The mean shoot length in the control was about $50 \%$ less than that in the two treatments. The difference was highly significant at $P<0.001$ in both seasons.

Table 1 Nutrient levels in a composite sample of soil from the experiment plot.

\begin{tabular}{llll}
\hline Soil nutrient & Quantity in soil & Assessment & Quantity in manure \\
\hline Total nitrogen (\%) & 0.21 & Adequate & 1.4 \\
Organic carbon (\%) & 2.14 & Adequate & - \\
Phosphorus (ppm) & 25 & Adequate & 0.49 \\
Potassium me (\%) & 1.33 & Adequate & 2.65 \\
Calcium me (\%) & 7.5 & Adequate & 2.2 \\
Magnesium me (\%) & 3.68 & Adequate & 0.42 \\
Manganese me (\%) & 0.43 & Adequate & 166 \\
Copper (ppm) & 2.60 & Adequate & 370 \\
Iron (ppm) & 48.6 & Adequate & 3,110 \\
Zinc (ppm) & 15.9 & Adequate & 138 \\
Sodium me (\%) & 0.66 & Adequate & - \\
\hline
\end{tabular}

-: no measurements were given from the soil labs.

Table 2 Total soil nitrogen in control (NF) subplots after harvest.

\begin{tabular}{lll}
\hline Sub-plot crop & Total nitrogen (\%) & Assessment \\
\hline Crotalaria & 0.23 & Adequate \\
Amaranthus & 0.23 & Adequate \\
\hline
\end{tabular}

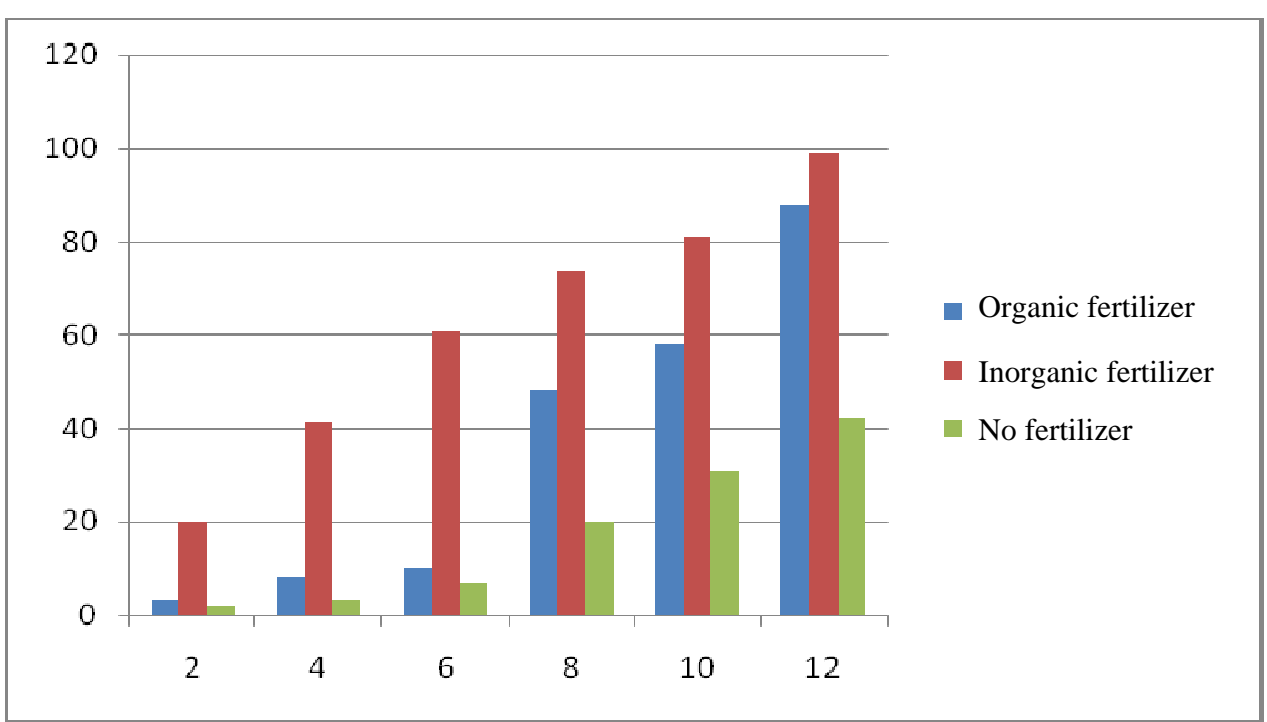

Fig. 1 Mean leaf number per plant in the treatments and control over 12 weeks in season one. 

Manangement-Crotolaria and Amaranth Farming

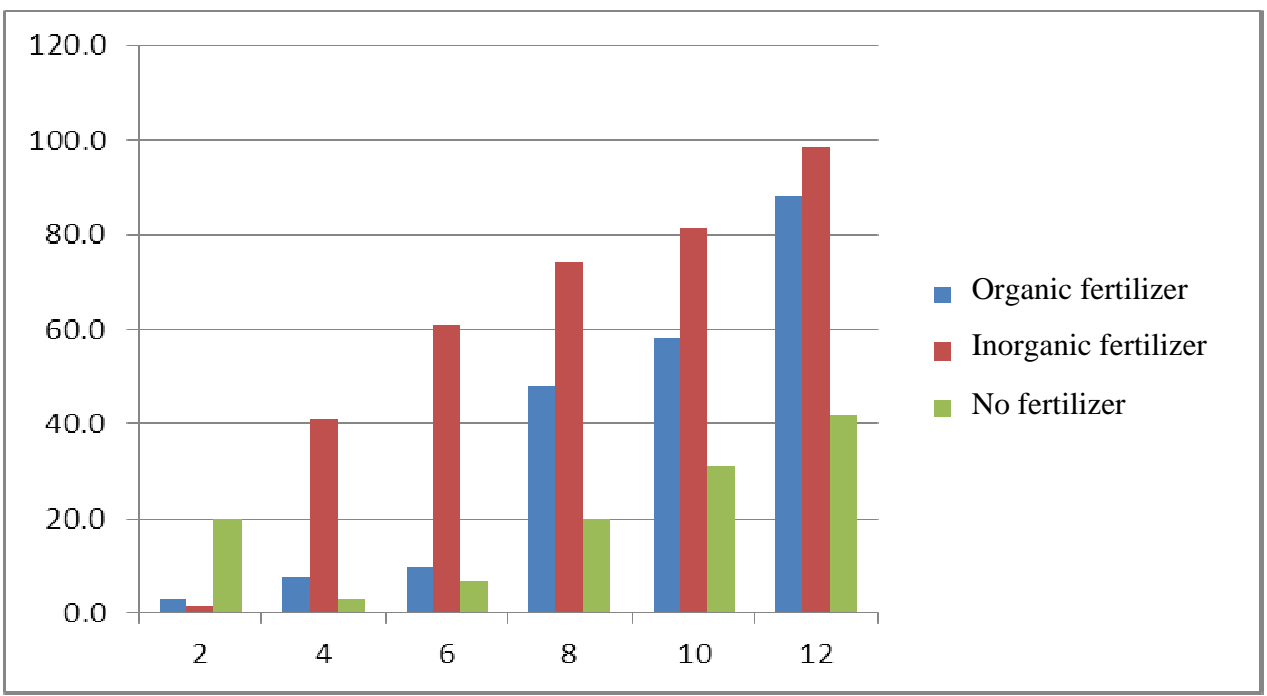

Fig. 2 Mean leaf number per plant in the treatments and control over 12 weeks in season two.

Table 3 Mean leaf number per plant in the treatments and control over 12 weeks in season one.

\begin{tabular}{llll}
\hline Week & Organic fertilizer & Inorganic fertilizer & No fertilizer \\
\hline 2 & 3 & 20 & 2 \\
4 & 8 & 41 & 3 \\
6 & 10 & 61 & 7 \\
8 & 48 & 74 & 20 \\
10 & 58 & 81 & 31 \\
12 & 88 & 99 & 42 \\
\hline
\end{tabular}

Table 4 Mean leaf number per plant in the treatments and control over 12 weeks in season two.

\begin{tabular}{llll}
\hline Week & Organic fertilizer & Inorganic fertilizer & No fertilizer \\
\hline 2 & 3 & 23 & 20 \\
4 & 8 & 41 & 3 \\
6 & 10 & 61 & 7 \\
8 & 48 & 74 & 20 \\
10 & 58 & 81 & 31 \\
12 & 88 & 99 & 42 \\
\hline
\end{tabular}

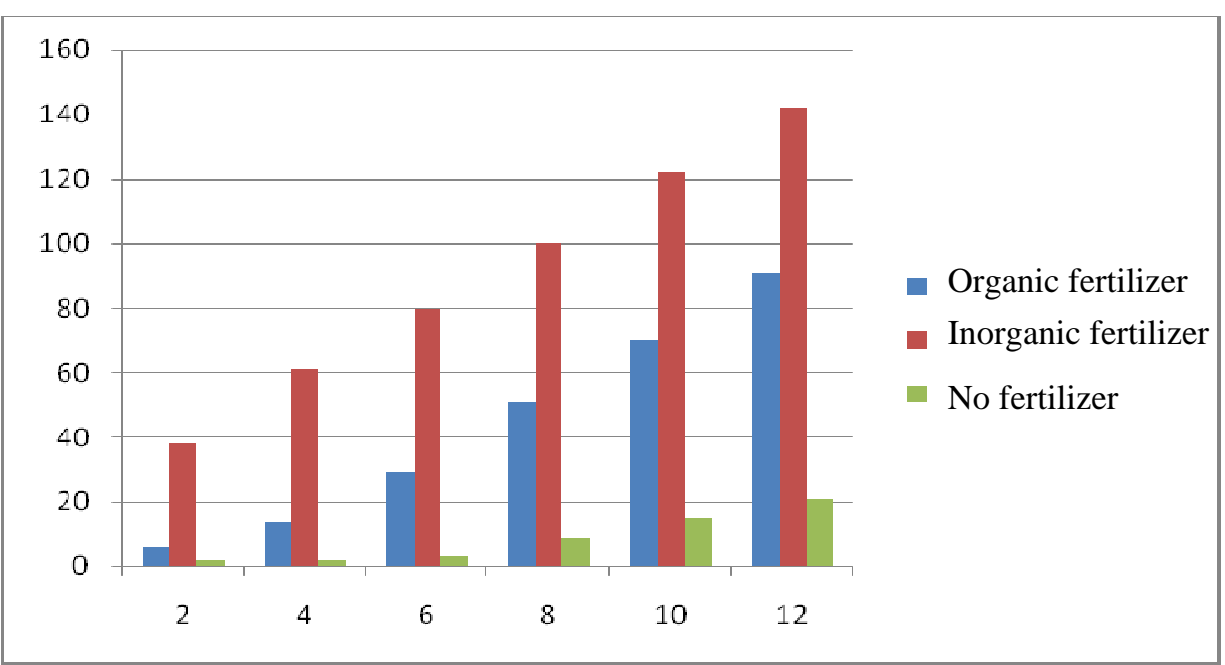

Fig. 3 Mean shoot length $(\mathrm{cm})$ in the treatments and control over 12 weeks in season one. 


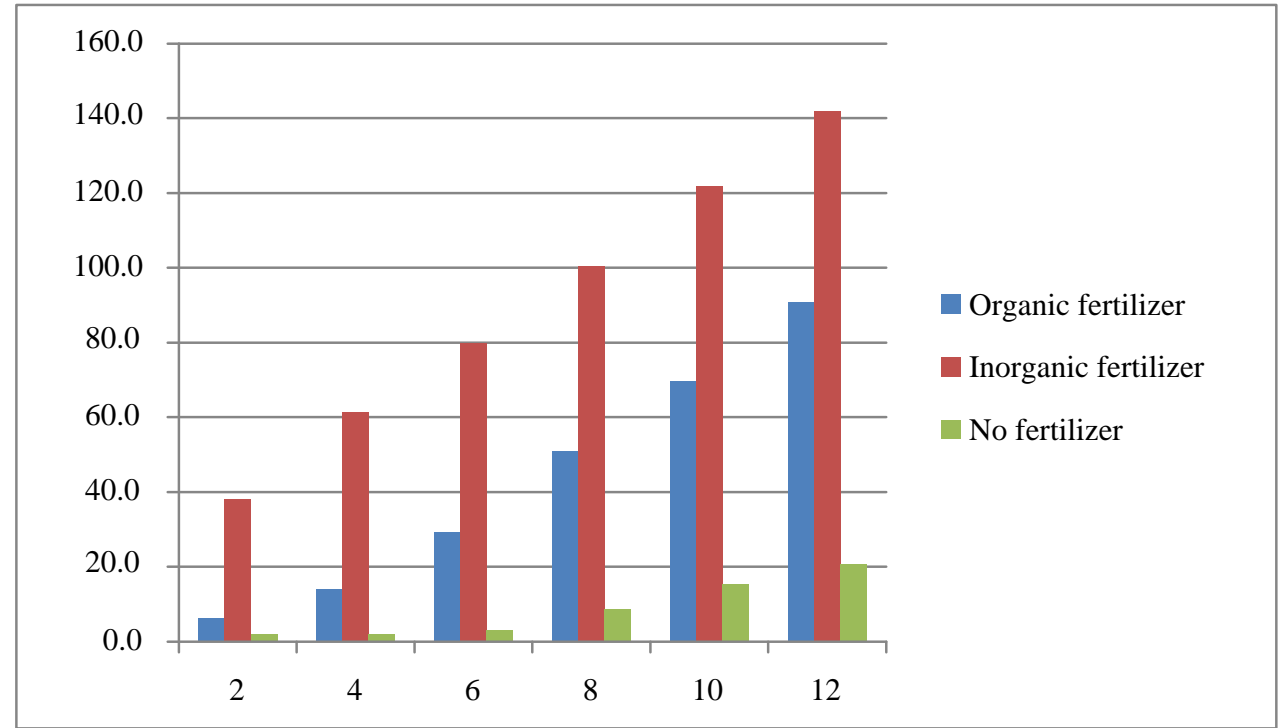

Fig. 4 Mean shoot length $(\mathrm{cm})$ in the treatments and control over 12 weeks in season two.

Table 5 Mean shoot length $(\mathrm{cm})$ in the treatments and control over 12 weeks in season one.

\begin{tabular}{llll}
\hline Week & Organic fertilizer & Inorganic fertilizer & No fertilizer \\
\hline 2 & 6 & 37 & 4 \\
4 & 14 & 59 & 5 \\
6 & 29 & 78 & 2 \\
8 & 51 & 102 & 9 \\
10 & 70 & 126 & 17 \\
12 & 91 & 139 & 25 \\
\hline
\end{tabular}

Table 6 Mean shoot length $(\mathrm{cm})$ in the treatments and control over 12 weeks in season two.

\begin{tabular}{llll}
\hline Week & Organic fertilizer & Inorganic fertilizer & No fertilizer \\
\hline 2 & 4 & 38 & 2 \\
4 & 13 & 61 & 2 \\
6 & 29 & 80 & 3 \\
8 & 50 & 100 & 9 \\
10 & 76 & 122 & 15 \\
12 & 98 & 142 & 21 \\
\hline
\end{tabular}

\subsubsection{Dry Weight}

High dry weight values were recorded in both seasons for the IF treatment (Figs. 5 and 6, Tables 7 and 8). The NF treatment in season one had values almost 50\% less than the other treatments. The NF treatment had a significant difference in season two with $P<0.05$.

\subsection{Crotalaria brevidens}

\subsubsection{Leaf Number}

There were no significant differences between the two treatments throughout both seasons, although the NF treatment plants had the greater leaf number towards the end of the growing season (Figs. 7 and 8, Tables 9 and 10). The differences in mean leaf number between the two treatments and the control were however not significant.

\subsubsection{Shoot Length}

The NF treatment was the highest almost throughout the treatment for the two seasons (Figs. 9 and 10, Tables 11 and 12). There was no significant difference between the treatments and control in both seasons. However, it was noted that OF treatment in both seasons recorded the highest values between the 4th week and the 10th week. 


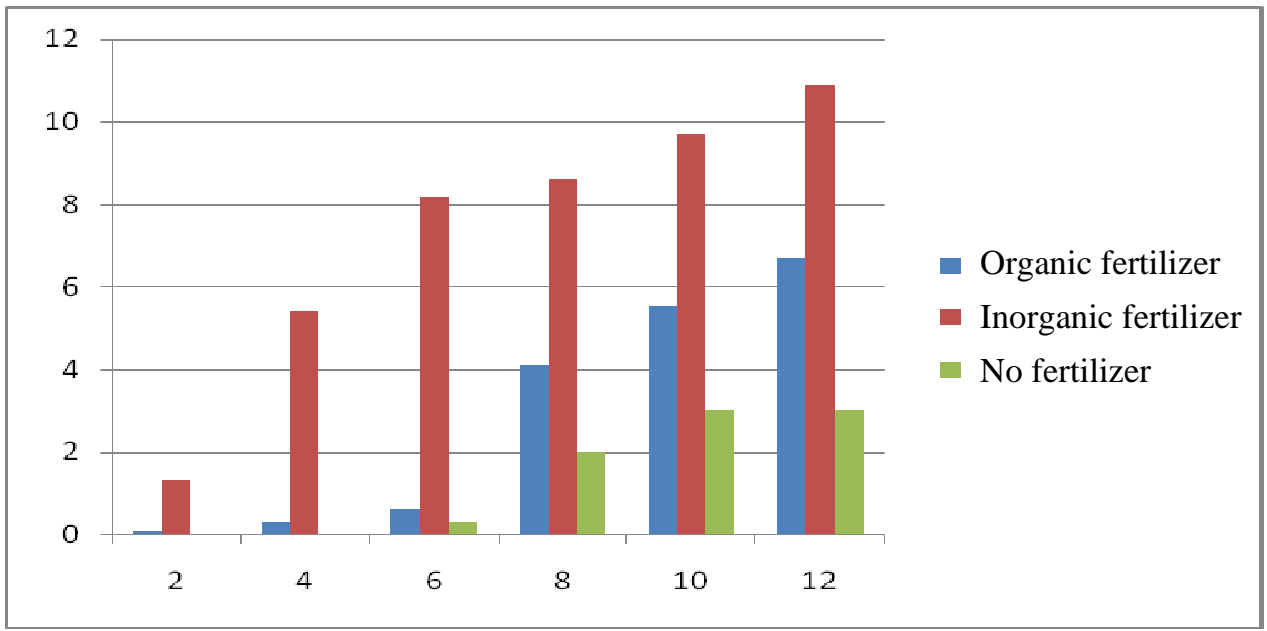

Fig. 5 Mean dry weight in the treatments and control over 12 weeks in season one.

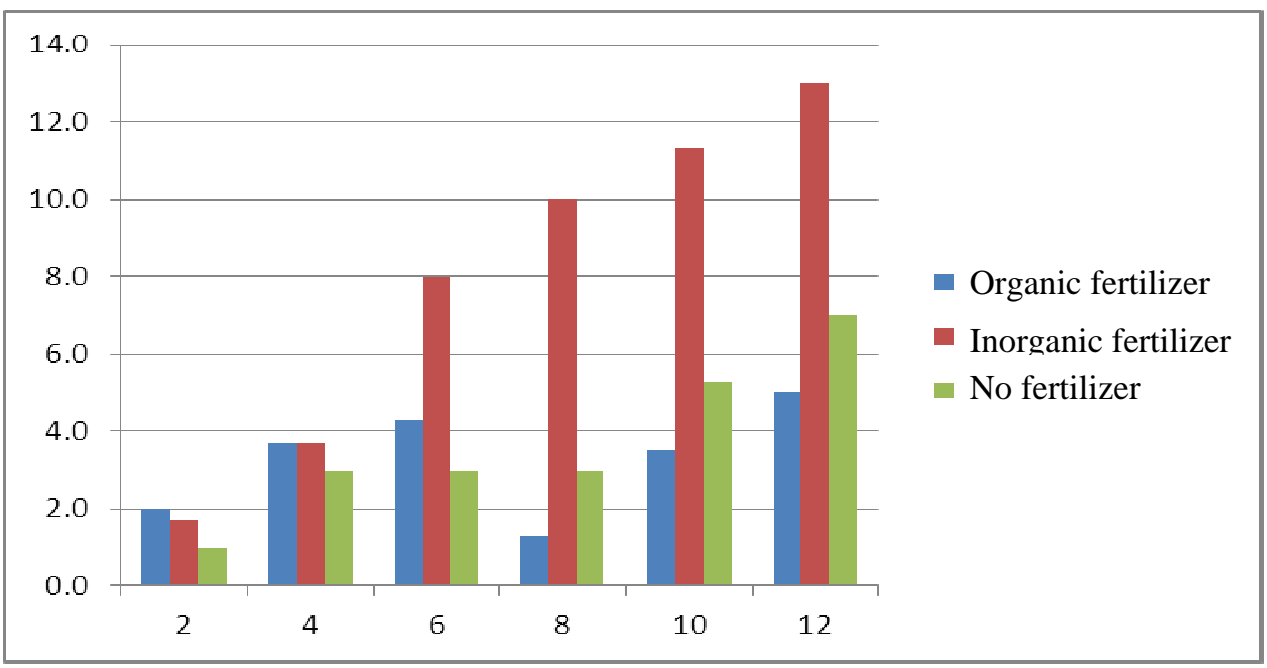

Fig. 6 Mean dry weight in the treatments and control over 12 weeks in season two.

Table 7 Mean dry weight (g) in the treatments and control over 12 weeks in season one.

\begin{tabular}{llll}
\hline Week & Organic fertilizer & Inorganic fertilizer & No fertilizer \\
\hline 2 & 0.1 & 1.3 & 0 \\
4 & 0.3 & 5.4 & 0 \\
6 & 0.6 & 8.2 & 0.3 \\
8 & 4.1 & 8.6 & 2.0 \\
10 & 5.5 & 9.7 & 3.0 \\
12 & 6.7 & 10.9 & 3.0 \\
\hline
\end{tabular}

Table 8 Mean dry weight (g) in the treatments and control over 12 weeks in season two.

\begin{tabular}{llll}
\hline Week & Organic fertilizer & Inorganic fertilizer & No fertilizer \\
\hline 2 & 2.0 & 1.7 & 1.0 \\
4 & 3.7 & 3.7 & 3.0 \\
6 & 4.3 & 8.0 & 3.0 \\
8 & 1.3 & 10.0 & 3.0 \\
10 & 3.5 & 11.3 & 5.3 \\
12 & 5.0 & 13.0 & 7.0 \\
\hline
\end{tabular}


African Traditional Vegetables as Agents of Integrated Soil Fertility Manangement-Crotolaria and Amaranth Farming

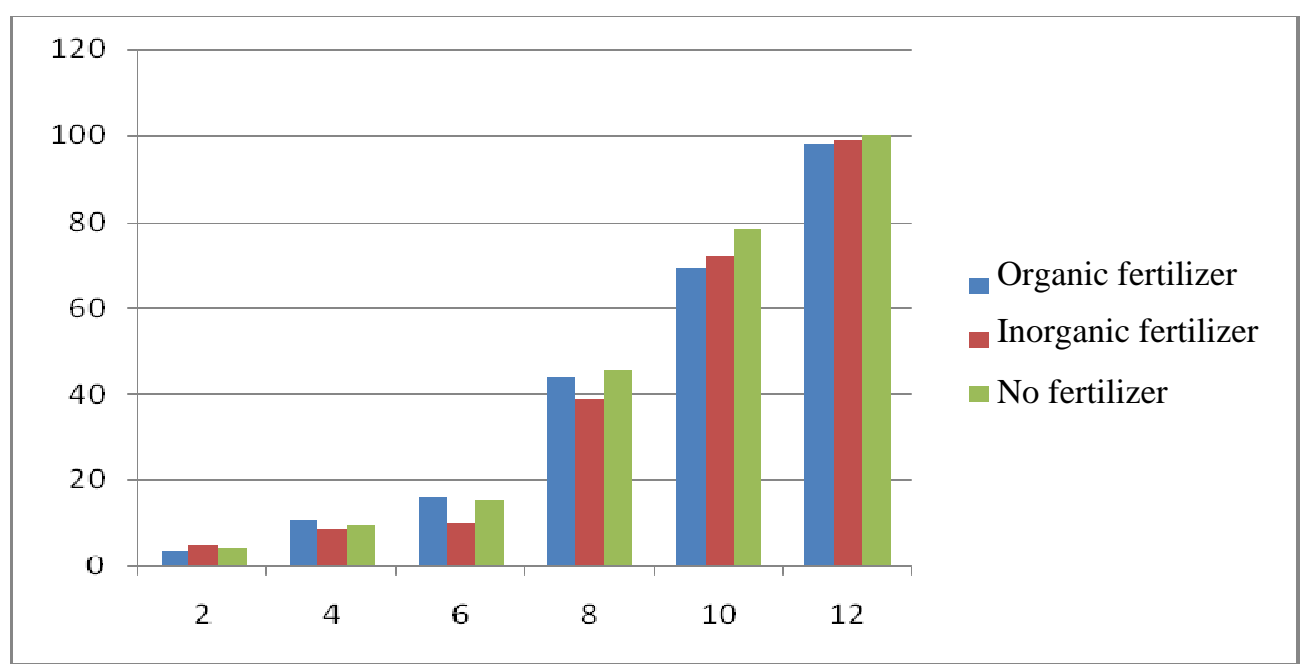

Fig. 7 Mean leaf number per plant in the treatments and control over 12 weeks in season one.

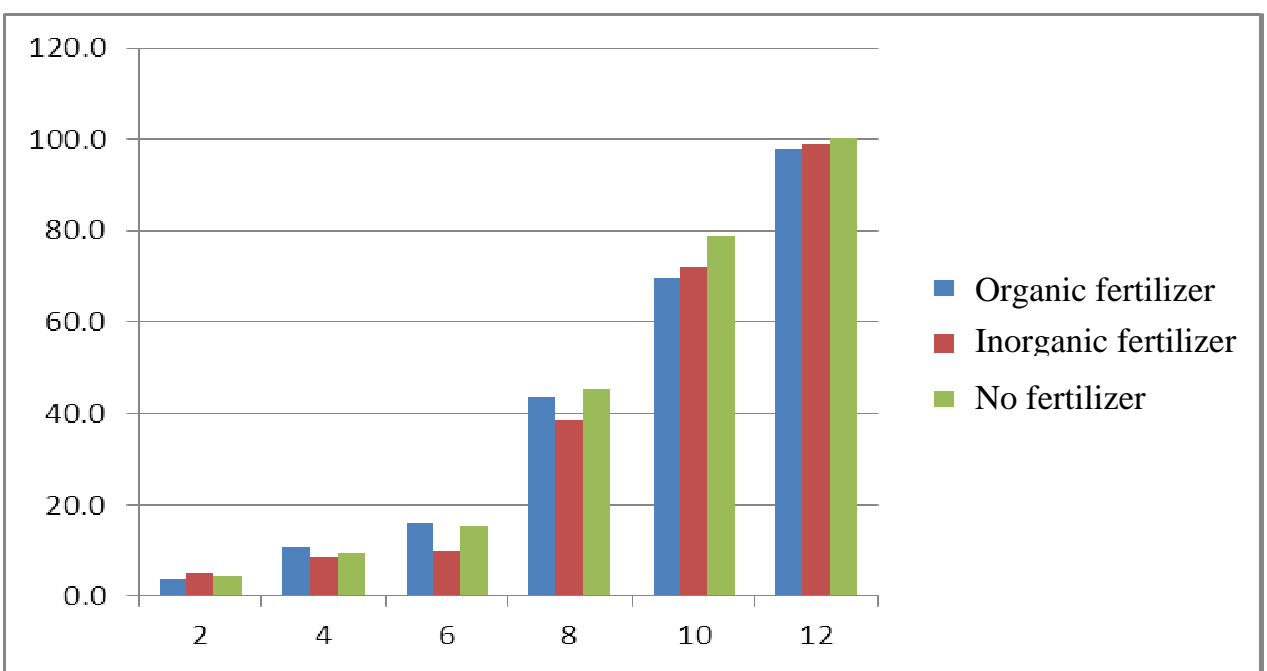

Fig. 8 Mean leaf number per plant in the treatments and control over 12 weeks in season two.

Table 9 Mean leaf number per plant in the treatments and control over 12 weeks in season one.

\begin{tabular}{llll}
\hline Week & Organic fertilizer & Inorganic fertilizer & No fertilizer \\
\hline 2 & 4 & 5 & 4 \\
4 & 11 & 9 & 10 \\
6 & 16 & 10 & 15 \\
8 & 44 & 39 & 45 \\
10 & 69 & 72 & 79 \\
12 & 98 & 99 & 100 \\
\hline
\end{tabular}

Table 10 Mean leaf number per plant in the treatments and control over 12 weeks in season two.

\begin{tabular}{llll}
\hline Week & Organic fertilizer & Inorganic fertilizer & No fertilizer \\
\hline 2 & 6 & 7 & 7 \\
4 & 12 & 9 & 13 \\
6 & 18 & 11 & 16 \\
8 & 47 & 38 & 46 \\
10 & 65 & 70 & 79 \\
12 & 94 & 97 & 101 \\
\hline
\end{tabular}




\subsubsection{Dry Weight}

The NF treatment was the highest in both seasons, even though the values obtained in season two were almost the same for all treatments (Figs. 11 and 12, Tables 13 and 14). There was no significant difference between the control and the other two treatments in both seasons.

3.3.4 Nodule Number

The NF treatment recorded the highest number of nodules in both seasons (Figs. 13 and 14, Tables 15 and 16). The OF and IF treatments had almost the same number of nodules in both seasons. The mean number of nodules per plant increased as the plants grew. The values for the two treatments were almost the same in both seasons, but any differences between the value of two treatments and the control were not significant.

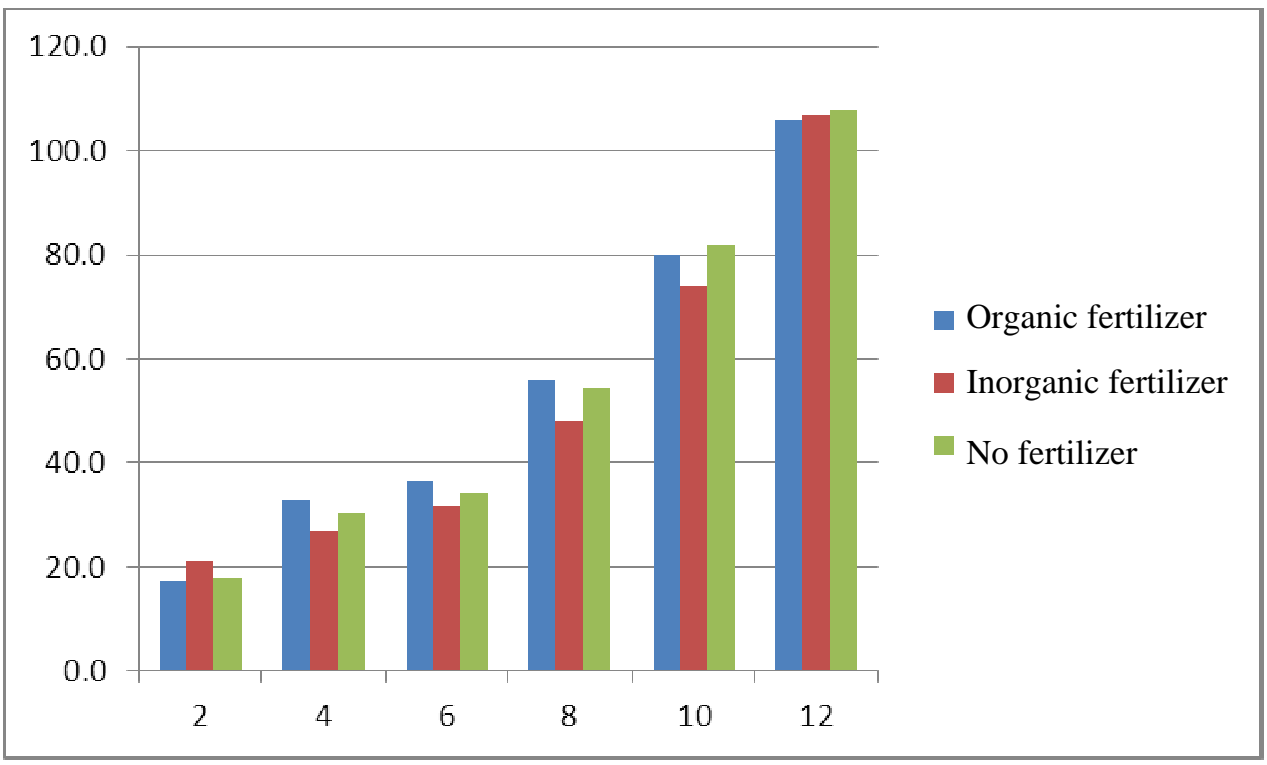

Fig. 9 Mean shoot length $(\mathrm{cm})$ in the treatments and control over 12 weeks in season one.

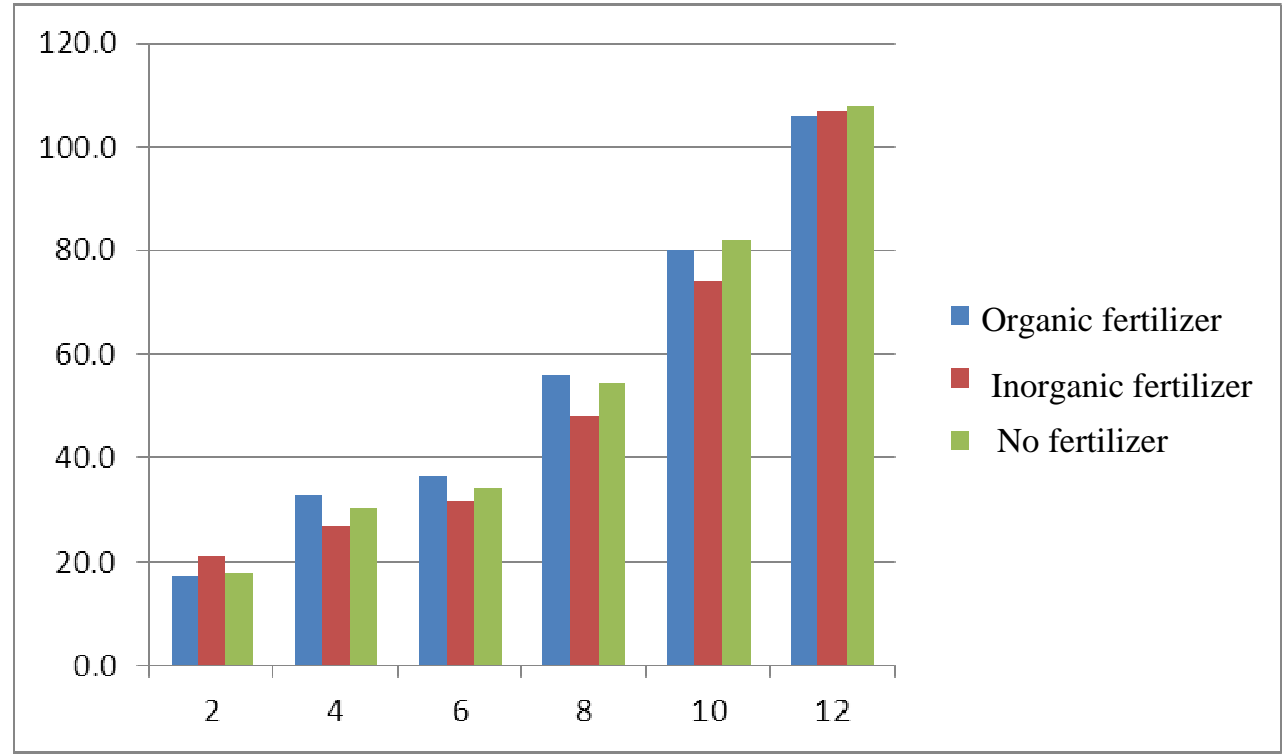

Fig. 10 Mean shoot length $(\mathrm{cm})$ in the treatments and control over 12 weeks in season two. 
African Traditional Vegetables as Agents of Integrated Soil Fertility

Manangement-Crotolaria and Amaranth Farming

Table 11 Mean shoot length $(\mathrm{cm})$ in the treatments and control over 12 weeks in season one.

\begin{tabular}{llll}
\hline Week & Organic fertilizer & Inorganic fertilizer & No fertilizer \\
\hline 2 & 17 & 21 & 18 \\
4 & 33 & 27 & 30 \\
6 & 36 & 32 & 34 \\
8 & 56 & 48 & 54 \\
10 & 80 & 74 & 82 \\
12 & 106 & 107 & 108 \\
\hline
\end{tabular}

Table 12 Mean shoot length $(\mathrm{cm})$ in the treatments and control over 12 weeks in season two.

\begin{tabular}{llll}
\hline Week & Organic fertilizer & Inorganic fertilizer & No fertilizer \\
\hline 2 & 19 & 19 & 14 \\
4 & 30 & 27 & 28 \\
6 & 38 & 30 & 36 \\
8 & 53 & 49 & 52 \\
10 & 79 & 71 & 79 \\
12 & 104 & 109 & 110 \\
\hline
\end{tabular}

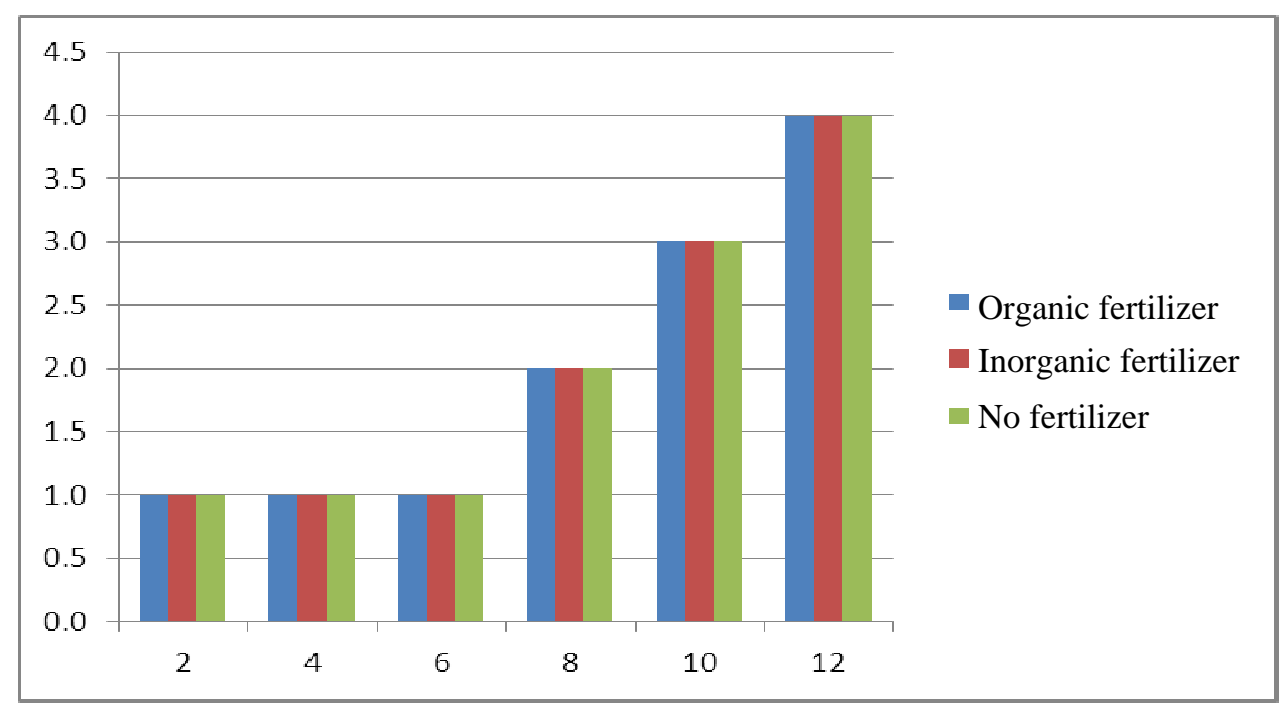

Fig. 11 Mean dry weight in the treatments and control over 12 weeks in season one.

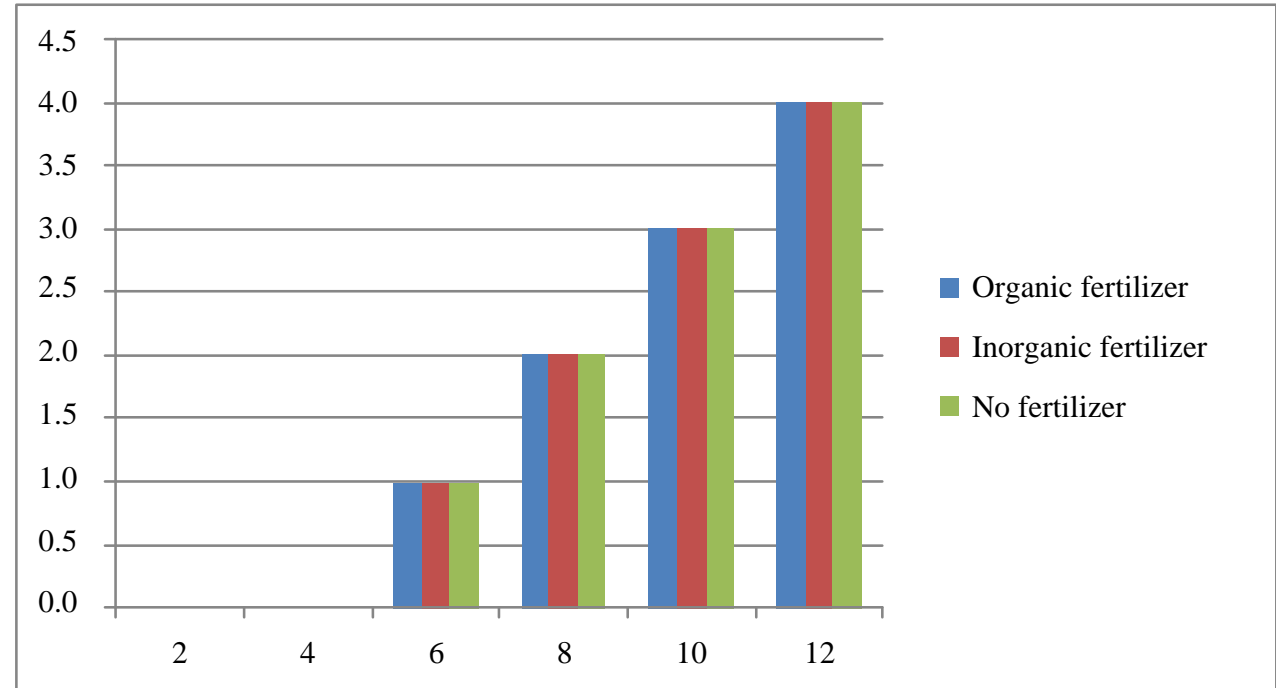

Fig. 12 Mean dry weight in the treatments and control over 12 weeks in season two. 
Table 13 Mean dry weight (g) in the treatments and control over 12 weeks in season one.

\begin{tabular}{llll}
\hline Week & Organic fertilizer & Inorganic fertilizer & No fertilizer \\
\hline 2 & 1 & 3 & 5 \\
4 & 1 & 1 & 2 \\
6 & 3 & 3 & 4 \\
8 & 3 & 3 & 5 \\
10 & 4 & 4 & 5 \\
12 & 4 & 4 & 5 \\
\hline
\end{tabular}

Table 14 Mean dry weight (g) in the treatments and control over 12 weeks in season two.

\begin{tabular}{llll}
\hline Week & Organic fertilizer & Inorganic fertilizer & No fertilizer \\
\hline 2 & & & \\
4 & 1 & & 1 \\
6 & 2 & 1 & 2 \\
8 & 3 & 2 & 3 \\
10 & 4 & 3 & 4 \\
12 & 4 & 4 & 4 \\
\hline
\end{tabular}

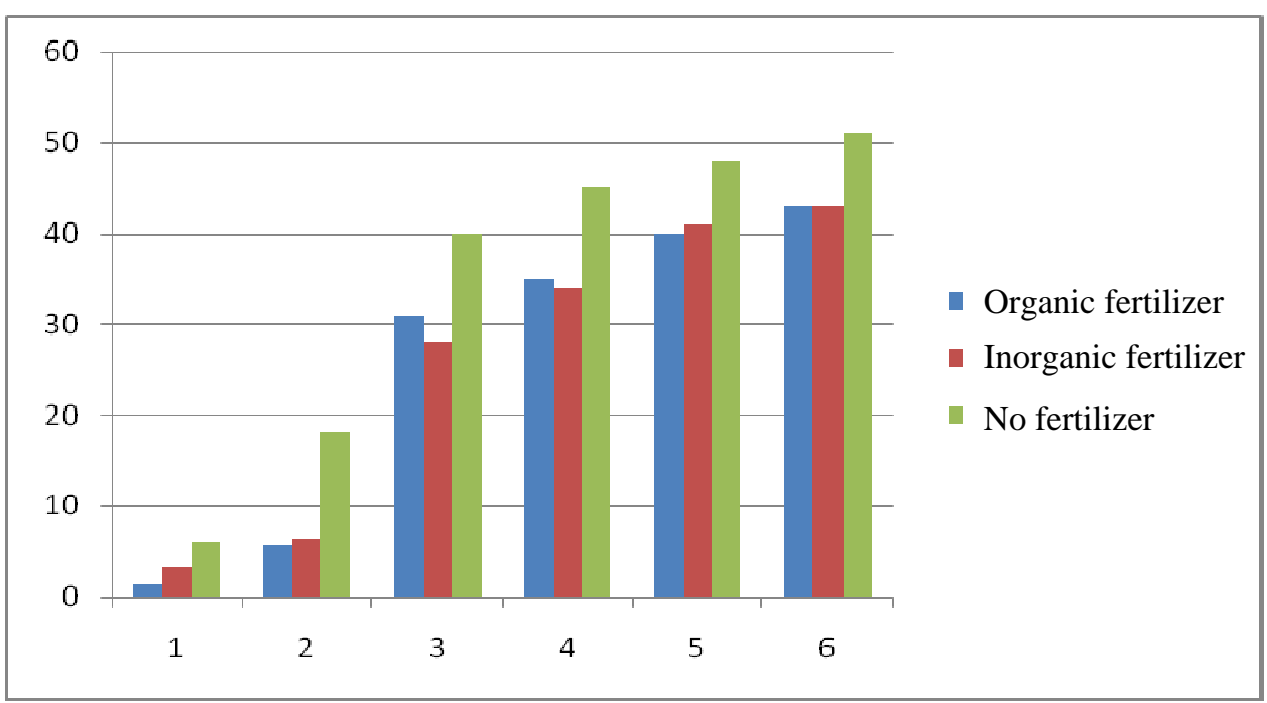

Fig. 13 Mean nodule numbers per plant in the treatments and control over 12 weeks in season one.

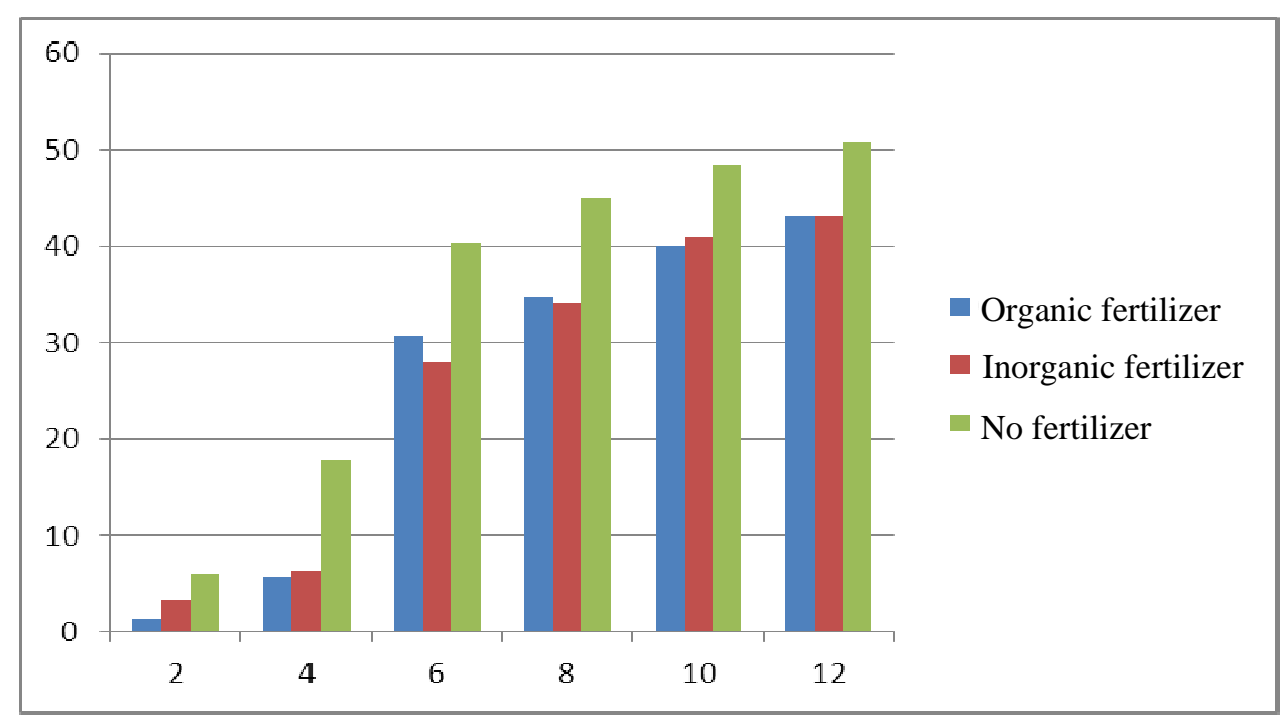

Fig. 14 Mean nodule numbers per plant in the treatments and control over 12 weeks in season two. 
Table 15 Mean nodule number in the treatments and control over 12 weeks in season one.

\begin{tabular}{llll}
\hline Week & Organic fertilizer & Inorganic fertilizer & No fertilizer \\
\hline 2 & 1 & 3 & 6 \\
4 & 5 & 6 & 18 \\
6 & 31 & 28 & 40 \\
8 & 35 & 34 & 45 \\
10 & 40 & 41 & 48 \\
12 & 43 & 43 & 51 \\
\hline
\end{tabular}

Table 16 Mean nodule number in the treatments and control over 12 weeks in season two.

\begin{tabular}{llll}
\hline Week & Organic fertilizer & Inorganic fertilizer & No fertilizer \\
\hline 2 & 1 & 3 & 6 \\
4 & 6 & 6 & 18 \\
6 & 31 & 28 & 40 \\
8 & 35 & 34 & 45 \\
10 & 40 & 41 & 48 \\
12 & 43 & 43 & 51 \\
\hline
\end{tabular}

\section{Discussion}

From the measurements of shoot length, leaf number, dry weight and nodule number, it was observed that Crotalaria responded well in the NF treatments in the two seasons. This was due to the fact that it fixes nitrogen through the nodules. It has been shown that when mineral nitrogen is depleted in the root zone of the legume, nitrogen fixation of legumes may be promoted.

Amba et al. [5] found that the presence of adequate quantities of phosphorous element in the soil was key to nitrogen fixation, and its value in Table 1 (pre-planting soil tests) indicated that the soils at the experiment site had adequate amounts of phosphorous. This meant that plants in the NF treatment were able to carry out nitrogen fixation well and thus the high values in the measured plant parameters. There was no significant boost of total soil nitrogen levels in the NF subplot for the legume Crotalaria, but this may become more evident with the trial over a longer term.

Amaranthus showed highly significant responses with additions of IF, as shown in its high values of leaf number, shoot length and dry matter accumulations. A notable observation with $\mathrm{OF}$ treatments in this crop was the surge in the measured parameters from around 10th week. This could be due to a synchrony factor where nutrient release was at its optimum during this week. This makes a case for the earlier application of organic fertilizers, such as a few weeks before sowing [6]. This aspect certainly merits further investigation.

Another factor to observe is that Crotalaria plants in the control plots (NF) did well throughout the two seasons and surpassed the plants in the IF and OF treatments. This can probably be explained by the fact that Crotalaria species do reduce plant-parasitic nematode populations, which tend to limit the intake of soil nitrates. More often than not, crop species, such as Crotalaria, are non-host or poor-host to several plant-parasitic nematodes. They also produce allelochemicals that are toxic, inhibitory or sticky to nematodes. Such compounds include pyrrolizidine, alkaloids and monocrotaline [7]. This explains why Crotalaria should be embraced by farmers in sustainable management of plant parasitic nematodes [8].

Given the economic challenges to smallholder farmers in applying sufficient IF in Kenya (and Africa in general), it would be recommended that the vegetable trial extend to an intercrop between leguminous and non-leguminous types and between cereals and leguminous vegetables in the small holder farms. Chandel et al. [9] found that cereal legume 
intercrops increased competition for soil nitrogen and hence resulted in the stimulation of nitrogen fixation. An alternative would be to grow the vegetable legumes immediately after the harvest of a cereal crop (when soil nitrogen levels are low) rather than after a fallow period, as this would stimulate the legumes to fix greater amounts of nitrogen [10]. An additional advantage of Crotalaria seeds is that they can be stored for a period of two years without significantly affecting their germination percentage and thus can be held in reserve for planting as an alternate crop to cereals [11].

In as much as use of organic manure is highly recommended, proper proportions should be applied. An over application results in organic manure building up in the soil to detrimental levels. The end result is excessive phosphate in the soil which polluted surface waters during run-offs. Nutrient excesses also "tie up" other minerals: excessive phosphate interferes with plant uptake of both copper and zinc; excessive potash can restrict boron, manganese and even magnesium [6].

Overall, the results obtained are indicative of the potential of leguminous vegetables as an important source of soil nitrogen in addition to their nutritive value.

\section{Conclusions}

At community and household level, knowledge associated with these vegetables is essentially passed on from one generation to the next; and in certain parts, there is the risk that this knowledge can be lost. Considering their potential nutritional value, indigenous and indigenized leafy vegetables could contribute in a major way to the food security and balanced diets of rural households. Due to their nutrient content and impact on soil chemistry, it is important to enhance the community roles of the African leafy that through further research and agronomic developments.

It is important to note that additional nitrogen applications had no significant effect on growth, leaf numbers and nodule numbers of Crotalaria brevidens. Such information will help in nutrient savings during planting and reduce the quantities of fertiliser applications especially if grown in rotation with non-leguminous crops.

\section{Recommendations}

ISFM has become a tool for improving crop production in sustainable agriculture. Therefore, traditional vegetables, which have the capability of adding nutrients and also regulating the soils conditions for suitable growing, should be embraced by smallholder farmers as a tool of ISFM. Pre-season or intercropping these vegetables with other crops that are not leguminous should be taken up by most of the smallholder farmers.

\section{Acknowledgments}

The research was successful courtesy of the Sustainable Development Initiatives Centre (SUDIC), United States International University (USIU) who provided the research assistants to help carry out the project for the two seasons in the SUDIC gardens. Kenya Agricultural Research Centre (KARI) carried out all the soil tests and advised on the quantities of fertilizers to apply.

\section{References}

[1] Sonja, V. L., Van Rensburg, J. W. S., Vorster, H. J., Van den Heever, E., and Van Zijl, J. J. B. 2007. "Promotion of African Leafy Vegetables within the Agricultural Research Council-Vegetable and Ornamental Plant Institute: The Impact of the Project." African Journal of Food Agriculture Nutrition and Development 7 (4): 144-9.

[2] Crewsa, T. E., and Peoples, M. B. 2004. "Legume Versus Fertilizer Sources of Nitrogen: Ecological Tradeoffs and Human Needs.” Agriculture, Ecosystems and Environment 102 (3): 279-97.

[3] Giller, K. E., and Cadisch, G. 1995. "Future Benefits from Biological Nitrogen Fixation: An Ecological Approach to Agriculture.” Plant and Soil 174 (1-2): 255-77.

[4] Ojiem, J. O., Vanlauwe, B., Ridder, N., and Giller, K. E. 

Manangement-Crotolaria and Amaranth Farming

2007. "Niche-Based Assessment of Contributions of Legumes to the Nitrogen Economy of Western Kenya Smallholder Farms.” Plant and Soil 292 (1-2): 119-35.

[5] Amba, A. A., Agbo, E. B., Voncir, N., and Oyawoye, M. O. 2011. "Effects of Phosphorus Fertilizers on Some Chemical Properties and Nitrogen Fixation of Legumes at Bauchi.” Continental Journal of Agriculture Science 5 (1): 39-43.

[6] Kuepper, G. 2003. "Manures for Organic Crop Production.” Accessed July 2013. http://www.attra.ncat.org/attrapub/PDF/manures.pdf.

[7] Wang, K. H., Sipes, B. S., and Schmitt, D. P. 2002. "Crotalaria as a Cover Crop for Nematode Management: A Review.” Nematropica 32 (1): 35-57.

[8] Omami, E., Njira, P. N., Kipkoech, A. K., Ngode, L., Obura, P., Ndinya, C., Mbogo, M., Cheruyout, H., and Ochuodho, J. O. 2012. "The Use of Crotalaria Species in
Sustainable Management of Plant-Parasitic Nematodes of Vegetable Crops in Western Kenya.” Presented at the Third RUFORUM Biennial Meeting, September 24-28, 2012, Chepkoilel University College, Moi University, Eldoret.

[9] Chandel, A. S., Panday, K. N., and Saxena, S. C. 1989. "Symbiotic Nitrogen Fixation and Nitrogen Benefits by Nodulated Soybean (Glycine max (L.) Merrill) to Interplanted Crops in Northern India.” Trop. Agric. 66 (1): 73-7.

[10] Peoples, M. B., Ladha, J. K., and Herridge, D. F. 1995. "Enhancing Legume $\mathrm{N}_{2}$ through Plant Management." Plant and Soil 174: 83-101.

[11] Abukutsa, O. M. 2007. "Response of Slender Leaf (Crotalaria brevidens Benth.) to Inorganic Nitrogen Application." Africa Journal of Food Agriculture Nutrition and Development 7 (3): 379-86. 